\title{
Fast-food exposure around schools in urban Adelaide
}

\author{
Neil T Coffee* ${ }^{*}$ Hannah P Kennedy and Theo Niyonsenga \\ Spatial Epidemiology and Evaluation Research Group, School of Health Sciences, Centre for Population Health \\ Research, Sansom Institute for Health Research, University of South Australia, North Terrace, Adelaide, SA 5000, \\ Australia
}

Submitted 25 November 2015: Final revision received 4 May 2016: Accepted 5 May 2016: First published online 14 June 2016

\begin{abstract}
Objective: To assess whether exposure to fast-food outlets around schools differed depending on socio-economic status (SES).

Design: Binary logistic regression was used to investigate the presence and zeroinflated Poisson regression was used for the count (due to the excess of zeroes) of fast food within $1000 \mathrm{~m}$ and $15000 \mathrm{~m}$ road network buffers around schools. The low and middle SES tertiles were combined due to a lack of significant variation as the 'disadvantaged' group and compared with the high SES tertile as the 'advantaged' group. School SES was expressed using the 2011 Australian Bureau of Statistics, socio-economic indices for areas, index of relative socio-economic disadvantage. Fast-food data included independent takeaway food outlets and major fast-food chains.

Setting: Metropolitan Adelaide, South Australia.

Subjects: A total of 459 schools were geocoded to the street address and $1000 \mathrm{~m}$ and $1500 \mathrm{~m}$ road network distance buffers calculated.

Results: There was a 1.6 times greater risk of exposure to fast food within $1000 \mathrm{~m}$ $(\mathrm{OR}=1.634 ; 95 \% 1.017,2.625)$ and a 9.5 times greater risk of exposure to a fast food within $1500 \mathrm{~m}(\mathrm{OR}=9.524 ; 95 \% \mathrm{CI} 3.497,25 \cdot 641)$ around disadvantaged schools compared with advantaged schools.

Conclusions: Disadvantaged schools were exposed to more fast food, with more than twice the number of disadvantaged schools exposed to fast food. The higher exposure to fast food near more disadvantaged schools may reflect lower commercial land cost in low-SES areas, potentially creating more financially desirable investments for fast-food developers.
\end{abstract}

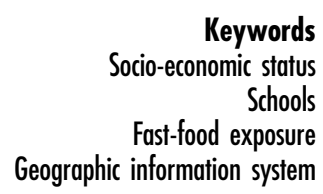

The rise of obesity, and in particular childhood obesity, was described as an epidemic by the WHO Expert Consultation on Obesity in $1997^{(1)}$ and has grown steadily since ${ }^{(2,3)}$. In 2013, Australia's prevalence of overweight and obesity as reported by the Global Burden of Disease Study was $24.4 \%$ for male youths ( $<20$ years of age) and $23.0 \%$ for female youths $^{(4)}$. The 2012 Australian Health Survey reported that $25 \%$ of children aged 2-17 years were overweight or obese. Similar rates were observed for 2-4-year-olds (23\%) and 1215 -year-olds (27\%), and for male (25\%) and female (26\%) adults $^{(5)}$.

Nutritional intake is recognised as a fundamental determinant of well-being as the type of food consumed defines to a large extent the individual's health status ${ }^{(6)}$. The consumption of high-energy, nutrient-poor fast food has been noted as a probable contributor to the increasing prevalence of obesity, particularly in developed countries $^{(1,7,8)}$.
In recent years, there has been greater acknowledgment of the role the built environment may play in influencing health outcomes associated with dietary choices ${ }^{(9-11)}$. Evidence suggests that the built environment and the food environment may play an important role in protecting and promoting human health. Yet, the majority of food environment studies occur in the USA, fewer in other developed countries ${ }^{(12)}$ and very few in Australia.

The relationship between socio-economic status (SES) and poor health, particularly obesity, is well documented. O'Dea $^{(13)}$ investigated the association of social class influences on childhood obesity among Australian schoolchildren and concluded that both male and female adolescents from low-SES backgrounds were more likely to be obese. This has influenced some researchers to investigate whether obesogenic environments are more prevalent in low-SES areas.

The notion of food environments within more disadvantaged areas being less conducive to healthy dietary 
choices such as higher fast-food exposure is supported by international studies ${ }^{(14-16)}$. One study in the UK did not support this relationship ${ }^{(17)}$, however, noting that the majority of fast-food outlets were located in the second least deprived quintile. The accessibility to food outlets, the quality of food available in fast-food outlets, socio-economic position and access to resources have all been implicated as potential intervention points to reduce the impact of unhealthful dietary behaviours.

Reidpath et $a l^{(18)}$ investigated the population per fast-food outlet density of postal districts in Melbourne, Australia, by SES recoded as weekly income quartiles. The study concluded that people living within the lowest SES quartile experienced 2.5 times greater exposure to fast-food outlets compared with individuals residing within the highest SES quartile. Moreover, their study suggested that lower-SES areas were potentially more obesogenic due to greater exposure to fast food. A similar study in Melbourne ${ }^{(9)}$ analysed SES and accessibility to supermarkets as a proxy for a healthy diet, as well as accessibility to fast food as a proxy for an unhealthy diet, and concluded that less advantaged areas have more access to fast-food outlets and poorer access to supermarkets compared with more advantaged areas.

The prevalence of overweight and obesity in children, particularly in low-SES communities, and the potential impact of the built environment on dietary behaviour have resulted in researchers investigating the food environment around schools by SES.

Children in low-SES areas are at an increased risk of developing obesity ${ }^{(19)}$ and the food environment around schools has been investigated as a potential cause and a target for health interventions. Day and Pearce ${ }^{(20)}$ investigated the spatial clustering of food outlets around schools of varying SES in New Zealand. Their study analysed the food environment within $1500 \mathrm{~m}$ of schools and concluded that the spatial clustering of fast-food outlets was highest nearby the most socially disadvantaged schools. This finding was reported in a number of studies ${ }^{(21-23)}$ from the USA and New Zealand, but not sustained by a study in Scotland ${ }^{(24)}$. A study in Los Angeles revealed an inverse relationship, where the association between SES and fast-food exposure within a $400 \mathrm{~m}$ buffer around schools occurred in areas with particularly high commercial density ${ }^{(21)}$.

A study in Montreal, Canada ${ }^{(25)}$ investigated the food environment within a $750 \mathrm{~m}$ buffer around primary and secondary schools ( $n$ 1168) by SES. The study concluded that schools located in the lowest income quartile areas experienced ten times more food retail outlets compared with schools located in the highest income quartile areas. Additionally, in relation to fast-food exposure, the study concluded that $81 \%$ of schools proximal to a fast-food outlet were located in the most deprived quartile areas. Consequently, only $12 \%$ of schools with exposure to fast food were situated in the most advantaged areas of
Montreal. Furthermore, the study noted that the built environment around schools as well as transport routes both to and from schools were potential targets for public health intervention policies.

Such investigation has not been carried out in South Australia even though in 2012 the prevalence of childhood obesity in Australia was approximately $25 \%{ }^{(5)}$. The present research investigated whether low-SES schools had higher exposure to fast-food retailers in metropolitan Adelaide. The research question for the current study tested whether the exposure to fast-food outlets around schools in metropolitan Adelaide differed depending on SES status. The two hypotheses for the statistical analyses were:

1. Fast-food exposure would be higher within $1000 \mathrm{~m}$ and $1500 \mathrm{~m}$ around schools located in disadvantaged areas.

2. The association between the relative exposure to fast food and area-level SES would remain significant even after controlling for density of the overall food environment.

\section{Methodology}

\section{Study area}

The study area encompassed metropolitan Adelaide, the capital of South Australia, which is approximately $80 \mathrm{~km}$ north-south and 30-40 km east-west (Fig. 1), with an estimated resident population of 1.2 million in $2011^{(26)}$. Adelaide is a low-density city (638 persons $/ \mathrm{km}^{2}$ ), charaterised by single dwellings ( $76 \%$ of dwellings) on large land parcels ${ }^{(26)}$.

\section{Socio-economic status}

School SES was expressed using the 2011 Australian Bureau of Statistics' socio-economic indices for areas $\left(\right.$ SEIFA) ${ }^{(27)}$ index of relative socio-economic disadvantage (IRSD) measured at the statistical area one level (SA1) that contained the school. The SA1 is the second smallest spatial unit designed by the Australian Bureau of Statistics for the Census of Population and Housing, and the smallest unit for the processing and release of Census data, and usually contains an average of 400 people (range of 200-800 people) ${ }^{(28)}$. SES was grouped into tertiles for the present research, but due to the lack of significant variation between the low and middle SES tertiles, they were combined into one 'low SES' group to be compared with the high-SES group. This method of comparing a section of the population at one end of the deprivation scale with the rest of the population is supported by previous studies investigating epidemiology of health outcomes, geographical trends and relationships with deprivation indices ${ }^{(29,30)}$. For the present research, the high-SES group was referred to as 'advantaged' and the rest of the population was referred to as 'disadvantaged'. 


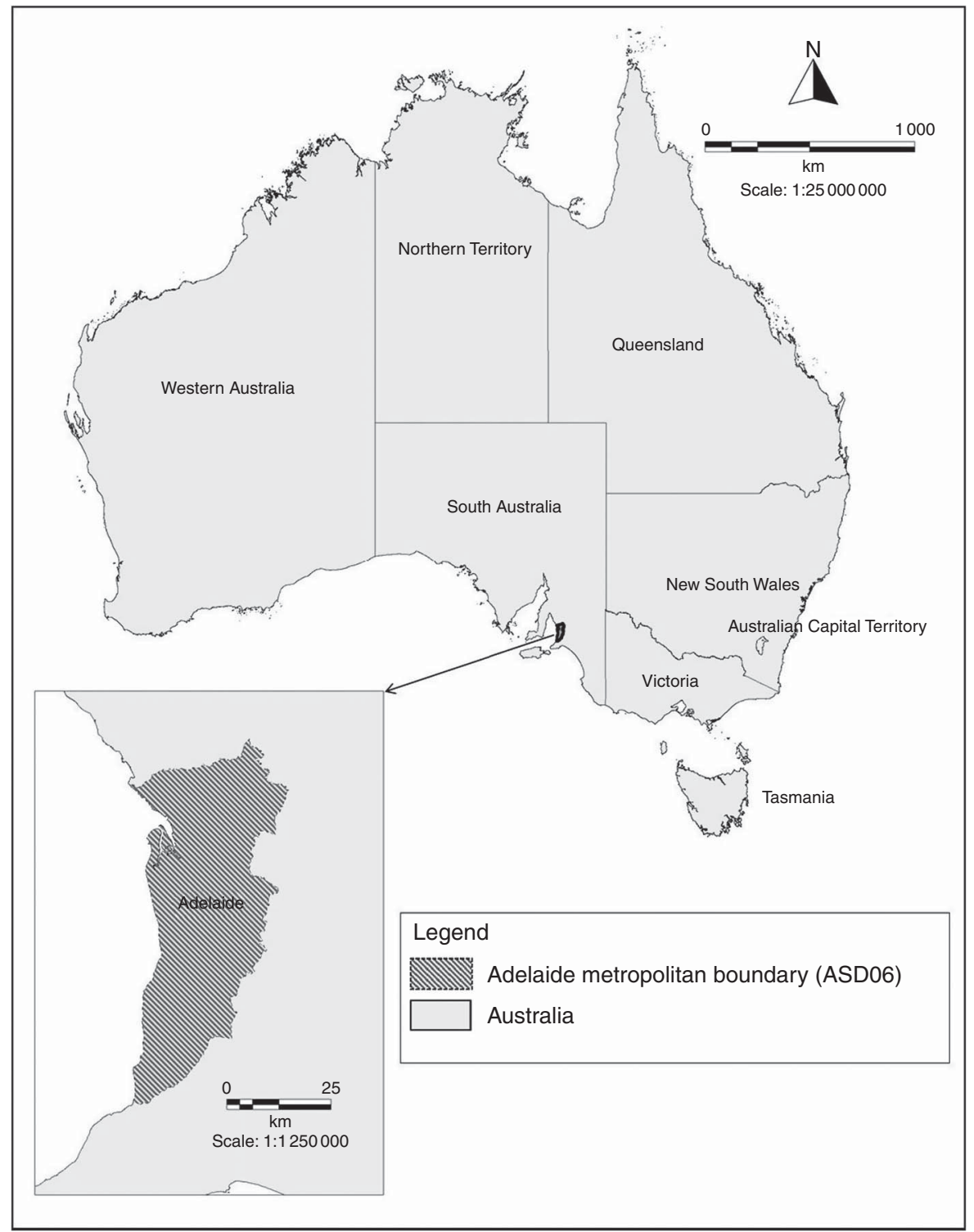

Fig. 1 Map of the study area

\section{School location}

The location of schools for 2011 within metropolitan Adelaide was sourced from the Department of Education and Community Services. The school data were checked for new schools or school closures between 2011 and 2013. The data set contained 459 schools, 308 primary, sixty-nine secondary, seventy reception to year 12 (R-12), one Indigenous and eleven specialised schools. Of these, fifteen were outside the urban area and not used for the current analysis. Due to the small volume of Indigenous and specialised schools, these schools were reclassified accordingly as primary, secondary or R-12 schools, resulting in three school categories. Each school was geocoded to the street address to enable the association with the SEIFA-IRSD and count of proximal fast-food outlets.

\section{Fast-food data set}

Fast-food data were taken from a retail food environment database developed for the present research and included independent takeaway food outlets such as pizza bars and fish and chip shops, as well as major fast-food franchises including McDonalds, Pizza Hut and Hungry Jacks (for a full list, see online supplementary material). The Sensis ${ }^{\mathrm{TM}}$ Yellow Pages ${ }^{\mathrm{TM}}$ (business telephone listing) food-related entries for the Adelaide metropolitan area were purchased using various search terms in December 2013 (Table 1). In order to capture the broadest possible food environment data set, any business that classified itself using one or more of these search terms was included.

The database initially contained 6305 records. The data cleaning process identified 497 records that were not food retailing or no longer operating, 176 duplicate records and 
Table 1 List of food environment search terms

\begin{tabular}{ll}
\hline Supermarkets \& Grocery Stores & Fish \& Seafood - Retail \\
Fruiterers \& Greengrocers & Food Delicacies \\
Halal Products & Confectionery - Retail \\
Kosher Products & Cake \& Pastry Shops \\
Restaurants & Bush Foods \& Ingredients \\
Cafés & Service Stations \\
Bakers & Food \&/or General Stores \\
Take Away Food & Delicatessens \\
Pizzas & Nuts - Edible \&/or Products \\
Health Foods \& Products - Retail & Juice Bars \\
Ice Cream - Retail & Shisha Café \\
Butchers - Retail & Frozen Foods - Retail \\
Poultry - Retail & Coffee - Retail \\
\hline
\end{tabular}

208 without full addresses. The corrected incomplete addresses and new records added 288, resulting in a final database of 5712. An additional check compared the Sensis data with website listings for the major retail chains to ensure all franchises were accounted for with accurate addresses. The data cleaning process was completed using a combination of online tools (NearMap, Google StreetView) and field ground-truthing. The outlets were then geocoded using their street address to provide a detailed spatial database of the food environment. The geocoding was undertaken using MapInfo Professional V12 and MapMarker V15 and the 2013 GNAF (geographic names address file). The final stage in producing the retail food environment database for metropolitan Adelaide involved checking the spatial accuracy. During the geocoding process, outlets within the retail food environment database were assigned codes to identify the level of accuracy of the geocode, with codes indicating a match to the street address, a street segment or just to the postcode. The location of the outlets with the least accurate geocode (street segment and postcode) was checked and moved to a more accurate location where possible. The final retail food environment database (2013) contained 5712 records. The use of web-based secondary data listings has been deployed by a number of research teams as a valid alternative to costly and timely field observation methods ${ }^{(31,32)}$.

\section{Spatial units}

In order to determine the accessibility of fast-food outlets around schools, road network distance buffers at $1000 \mathrm{~m}$ and $1500 \mathrm{~m}$ were calculated around each school using the 'Network Analyst' function in ArcMap V10·2 1. These distances represent on average a 10-12 $\mathrm{min}$ and $15-17 \mathrm{~min}$ walk, respectively ${ }^{(33)}$. As stated earlier, Adelaide is a very-low-density city and these distances represent a size more likely to capture other land uses. As certain school land parcels were quite large with the centre points situated a reasonable distance from the road network, all school centre points were moved to the closest road centreline and the road network buffer originated from this location. Road network data for South Australia were obtained from Pitney Bowes Pty Ltd for the year 2013 (StreetPro ${ }^{\mathrm{TM}}$; a commercial road network). Using the intersect function in MapInfo Professional V12, the retail database fast-food outlets were intersected with the school buffers to identify all retail outlets contained within each of the road network buffers (Fig. 2).

\section{Measures}

Fast-food measures for the present research were operationalised as dichotomised presence/absence and the count of fast-food outlets. Two additional variables were calculated, zoning within each buffer distance and kernel density, to investigate the density of food retail outlets across the study area. The zoning data were sourced from the South Australian Department of Planning, Transport and Infrastructure (2013) via the publically available www.sa.gov website. This was a detailed spatial data set that specified the zoning for all land parcels in South Australia. For the present analysis, retail zoning was extracted from the database to enable the percentage of retail zoning around schools to be calculated. Kernel density is useful to calculate the density of events across a surface by calculating the overall number of cases situated within a given search radius ${ }^{(34)}$. The spatial density of food outlets within metropolitan Adelaide was assessed using kernel density calculations via $1000 \mathrm{~m}$ and $1500 \mathrm{~m}$ bandwidths for each buffer. As applied elsewhere ${ }^{(25)}$, the kernel calculations were classified into density tertiles to observe if the retail food environment within each school buffer was of low, medium or high density.

\section{Statistical analysis}

Binary logistic regression was used to investigate the associations between school SES and the presence of fast food within the $1000 \mathrm{~m}$ and $1500 \mathrm{~m}$ road network buffers around schools. For the count of fast food within the $1000 \mathrm{~m}$ and $1500 \mathrm{~m}$ road network buffers, the zero-inflated Poisson regression model was used (due to the excess of zeroes in the count data). The zero-inflated Poisson regression model takes into account the presence of excess zeroes in the data assuming that there are two processes that generated the data. These processes result into two possible groups, 'non-certain zero' and 'certain zero'. The 'certain zero' group of schools without fast food around can be understood as the schools residing in areas where, because of the zoning, it was impossible to build any food retail outlet. In areas where the zoning allows for the presence of food retail outlets, the zero fast-food outlets is part of the random Poisson process counting the number of fast-food retail outlets. The membership to the 'certain zero' group is modelled using logistic regression to predict the odds of membership to the 'certain zero', with retail zoning as a predictor variable. The statistical significance was set at $\alpha=5 \%$. Analyses were restricted to 


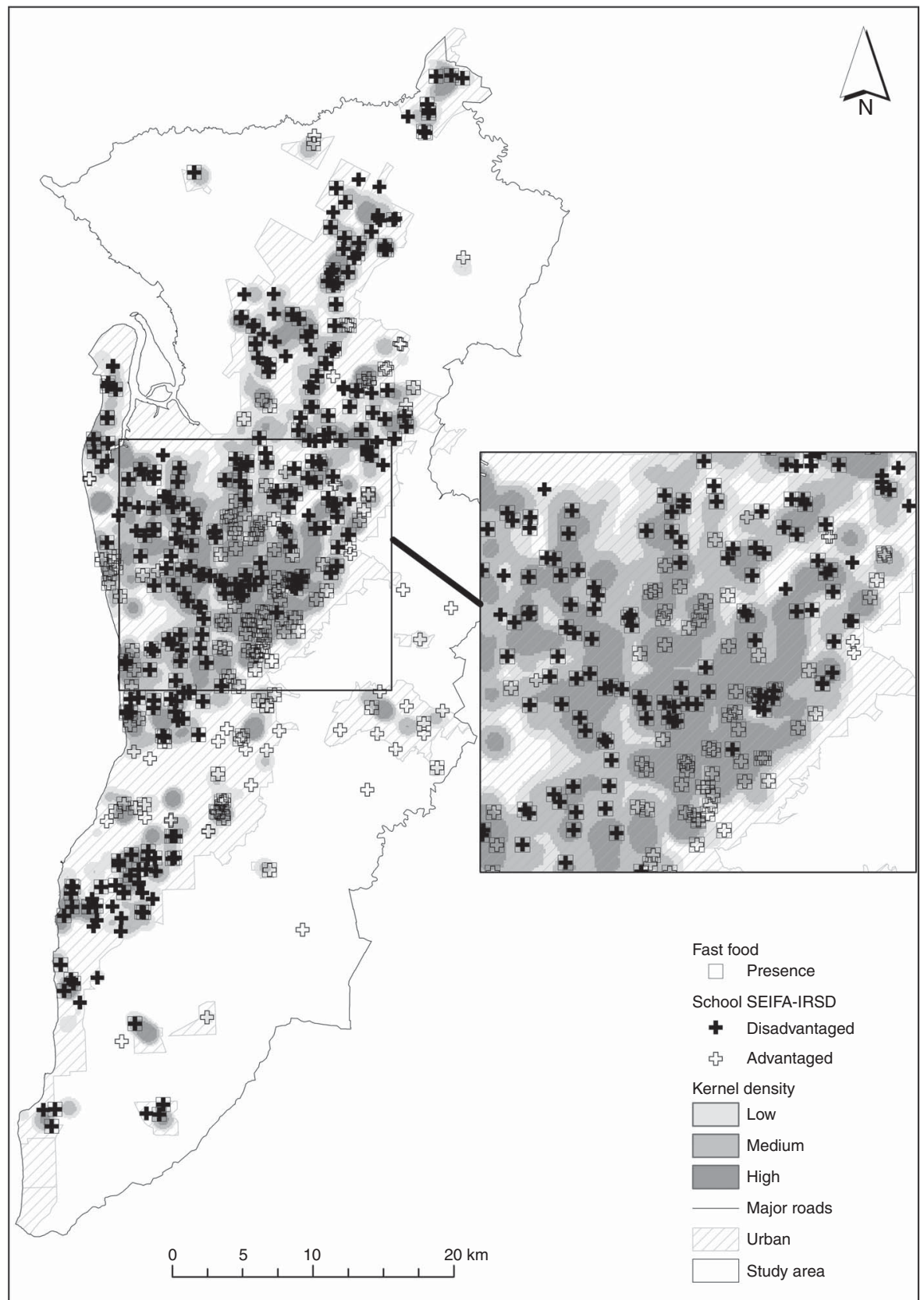

Fig. 2 School, fast-food location and kernel density, metropolitan Adelaide, South Australia, 2013 (SEIFA-IRSD, Australian Bureau of Statistics' socio-economic indices for areas ${ }^{(27)}$ index of relative socio-economic disadvantage)

schools in urban areas and excluded schools with missing SEIFA-IRSD values ( $n$ 444).

\section{Results}

\section{Descriptive statistics}

As of June 2011, there were 444 schools in the Adelaide metropolitan area. The exposure to fast-food outlets by school disadvantage/advantage is shown in Table 2 . The presence of fast food was highest for disadvantaged schools for both the $1000 \mathrm{~m}$ buffer and the $1500 \mathrm{~m}$ buffer ( $55 \%$ and $66 \%$ compared with $24 \%$ and $28 \%$ ).

There was a greater presence of fast-food outlets surrounding schools located in disadvantaged areas for both the buffers. Of the schools exposed to fast food, $70 \%$ (246 out of 352 and 295 out of 419, respectively) in both the $1000 \mathrm{~m}$ and $1500 \mathrm{~m}$ buffer were in the disadvantaged group. Of the disadvantaged schools, 98\% (295 out of 300) were exposed to fast food within $1500 \mathrm{~m}$, compared with $86 \%$ (124 out of 144) of advantaged schools. Of the disadvantaged/advantaged schools exposed to fast food 
(352 and 419, respectively, in $1000 \mathrm{~m}$ and $1500 \mathrm{~m}$ ), $70 \%$ in both the $1000 \mathrm{~m}$ and $1500 \mathrm{~m}$ buffer were in the disadvantaged group. There was a greater presence of fast-food outlets surrounding public schools located in disadvantaged area for both the buffers. Almost double the number of public schools in disadvantaged areas were exposed to fast-food outlets ( $220 v .132$ for the $1000 \mathrm{~m}$ and $267 v .152$ for the $1500 \mathrm{~m}$ buffers, respectively). The risk of retail zoning was more likely around disadvantaged schools than advantaged schools, with more than twice the number of disadvantaged schools containing zoning that allowed retail activity within the $1000 \mathrm{~m}$ and $1500 \mathrm{~m}$ buffers.

The mean count of fast-food outlets within $1000 \mathrm{~m}$ and $1500 \mathrm{~m}$ around schools was higher for schools located in disadvantaged areas (11.1 and 22.5) compared with schools located in advantaged areas (6.7 and $14 \cdot 2$; Fig. 3 ). On average, within the $1500 \mathrm{~m}$ buffer there were eight more fast-food outlets around disadvantaged schools compared with advantaged schools.

Schools located in disadvantaged areas also recorded a higher maximum count of fast-food outlets for both the $1000 \mathrm{~m}$ buffer and the $1500 \mathrm{~m}$ buffer compared with the maximum number of fast-food outlets around schools in the advantaged areas (Table 3). However, there is a high SD for the count of fast-food outlets around schools in disadvantaged areas. This is likely caused by schools situated within Adelaide's Central Business District, where there is an exceptionally high volume of retail fast-food outlets compared with the surrounding residential areas.

Table 4 displays the results of the binary logistic regression model relating the exposure to fast food (presence/absence of a retail fast-food outlet) to SES disadvantage/advantage and to food retail kernel density adjusting for retail zoning within the road network buffers around schools in metropolitan Adelaide. The

Table 2 School exposure to fast food by disadvantaged/advantaged socio-economic status, metropolitan Adelaide, South Australia, 2013

\begin{tabular}{|c|c|c|c|c|c|c|c|c|}
\hline \multirow[b]{2}{*}{ Buffer } & \multicolumn{2}{|c|}{ Presence } & \multicolumn{2}{|c|}{ Absence } & \multicolumn{2}{|c|}{ Presence } & \multicolumn{2}{|c|}{ Absence } \\
\hline & $n$ & $\%$ & $n$ & $\%$ & $n$ & $\%$ & $n$ & $\%$ \\
\hline & \multicolumn{4}{|c|}{ Disadvantaged ( $n$ 300) } & \multicolumn{4}{|c|}{ Advantaged ( $n$ 144) } \\
\hline $1000 \mathrm{~m}$ & 246 & $82 \cdot 0$ & 54 & $18 \cdot 0$ & 106 & $73 \cdot 6$ & 38 & $26 \cdot 4$ \\
\hline $1500 \mathrm{~m}$ & 295 & $98 \cdot 3$ & 5 & $1 \cdot 7$ & 124 & $86 \cdot 1$ & 20 & $13 \cdot 9$ \\
\hline & \multicolumn{4}{|c|}{ Public schools ( $n$ 290) } & \multicolumn{4}{|c|}{ Private/independent schools ( $n$ 154) } \\
\hline $1000 \mathrm{~m}$ & 220 & $75 \cdot 9$ & 70 & $24 \cdot 1$ & 132 & $85 \cdot 7$ & 22 & $14 \cdot 3$ \\
\hline $1500 \mathrm{~m}$ & 267 & $92 \cdot 1$ & 23 & 7.9 & 152 & $98 \cdot 7$ & 2 & $1 \cdot 3$ \\
\hline & \multicolumn{4}{|c|}{ Disadvantaged: zoning ( $n$ 300) } & \multicolumn{4}{|c|}{ Advantaged: zoning ( $n$ 144) } \\
\hline $1000 \mathrm{~m}$ & 243 & $81 \cdot 0$ & 57 & $19 \cdot 0$ & 101 & $70 \cdot 1$ & 43 & 29.9 \\
\hline $1500 \mathrm{~m}$ & 280 & 93.3 & 20 & $6 \cdot 7$ & 113 & $78 \cdot 5$ & 31 & 21.5 \\
\hline
\end{tabular}

Presence/absence means the presence (yes/no) of fast food.

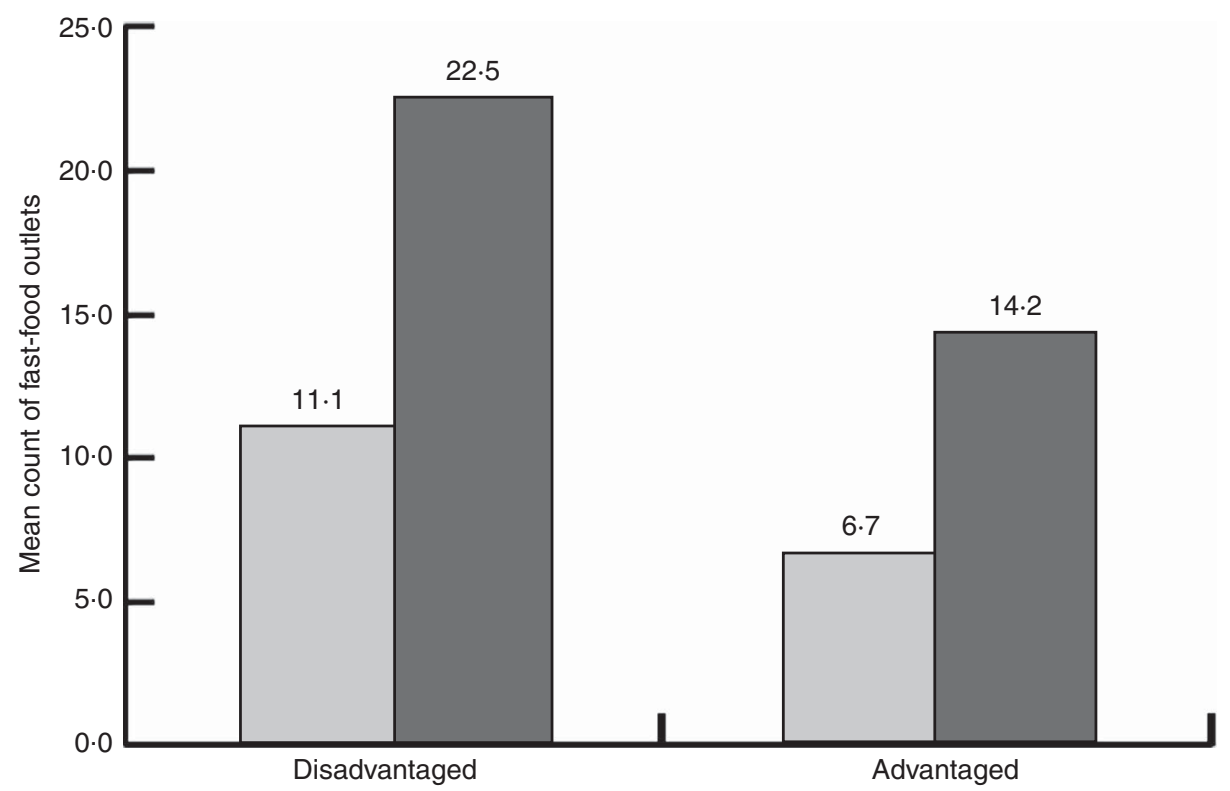

Fig. 3 Mean count of fast-food outlets within $1000 \mathrm{~m}(\square)$ and $1500 \mathrm{~m}$ ( $\square$ ) buffers around schools by disadvantaged/advantaged socio-economic status, metropolitan Adelaide, South Australia, 2013 
Table 3 Count of fast-food outlets by disadvantaged ( $n$ 300)/advantaged ( $n$ 144) socio-economic status (SES), metropolitan Adelaide, South Australia, 2013

\begin{tabular}{|c|c|c|c|c|c|c|}
\hline SES & Buffer & Minimum & Maximum & Mean & Median & SD \\
\hline \multirow[t]{2}{*}{ Disadvantaged areas } & $1000 \mathrm{~m}$ & 0 & 293 & $11 \cdot 1$ & 3.5 & 33.7 \\
\hline & $1500 \mathrm{~m}$ & 0 & 411 & 22.5 & $9 \cdot 0$ & $57 \cdot 1$ \\
\hline \multirow[t]{2}{*}{ Advantaged areas } & $1000 \mathrm{~m}$ & 0 & 43 & $6 \cdot 7$ & 3.5 & 8.8 \\
\hline & $1500 \mathrm{~m}$ & 0 & 69 & 14.2 & 9.0 & 16.0 \\
\hline
\end{tabular}

Table 4 Associations between fast-food exposure* and school disadvantaged/advantaged socio-economic status (SES) and food retail kernel density (K-density), adjusting for retail zoning within the road network buffers around schools, metropolitan Adelaide, South Australia, 2013

\begin{tabular}{|c|c|c|c|c|c|}
\hline \multirow[b]{2}{*}{ Binary logistic regression } & \multirow[b]{2}{*}{$\beta$ coefficient } & \multirow[b]{2}{*}{$P$ value } & \multirow[b]{2}{*}{$\mathrm{OR}=\exp (\beta)$} & \multicolumn{2}{|c|}{$95 \% \mathrm{Cl}$ for OR } \\
\hline & & & & Lower & Upper \\
\hline $\begin{array}{l}\text { SES disadvantaged } 1000 \mathrm{~m} \\
\text { SES disadvantaged } 1500 \mathrm{~m}\end{array}$ & $\begin{array}{l}0.490 \\
2 \cdot 253\end{array}$ & $\begin{array}{c}0.042 \\
<0.0001\end{array}$ & $\begin{array}{l}1.634 \\
9.524\end{array}$ & $\begin{array}{l}1 \cdot 017 \\
3.497\end{array}$ & $\begin{array}{r}2.625 \\
25 \cdot 641\end{array}$ \\
\hline $\begin{array}{l}\text { SES disadvantaged } \\
\text { K-density } 1000 \mathrm{~m} \text { (mid) } \\
\text { K-density } 1000 \mathrm{~m} \text { (high) }\end{array}$ & $\begin{array}{l}0.194 \\
1.914 \\
3.977\end{array}$ & $\begin{array}{l}0.503 \\
<0.0001 \\
<0.0001\end{array}$ & $\begin{array}{r}1.215 \\
6 \cdot 778 \\
53 \cdot 375\end{array}$ & $\begin{array}{r}0.687 \\
3.739 \\
16.201\end{array}$ & $\begin{array}{r}2 \cdot 146 \\
12 \cdot 288 \\
175 \cdot 854\end{array}$ \\
\hline $\begin{array}{l}\text { SES disadvantaged } \\
\text { K-density } 1500 \text { m (mid) } \\
\text { K-density } 1500 \text { m (high) }\end{array}$ & $\begin{array}{l}1.602 \\
3.629 \\
4.112\end{array}$ & $\begin{array}{l}0.004 \\
<0.0001 \\
<0.0001\end{array}$ & $\begin{array}{r}4.975 \\
37 \cdot 682 \\
61.095\end{array}$ & $\begin{array}{l}1.678 \\
4.859 \\
8.003\end{array}$ & $\begin{array}{r}14 \cdot 706 \\
292 \cdot 196 \\
466 \cdot 294\end{array}$ \\
\hline $\begin{array}{l}\text { SES disadvantaged } \\
\text { K-density } 1000 \mathrm{~m} \text { (mid) } \\
\text { K-density } 1000 \mathrm{~m} \text { (high) } \\
\text { Retail zoning } 1000 \mathrm{~m}\end{array}$ & $\begin{array}{l}0.016 \\
1.841 \\
3.743 \\
1.058\end{array}$ & $\begin{array}{r}0.9593 \\
<0.0001 \\
<0.0001 \\
0.0004\end{array}$ & $\begin{array}{r}1 \cdot 016 \\
6 \cdot 302 \\
42 \cdot 216 \\
2 \cdot 881\end{array}$ & $\begin{array}{r}0.556 \\
3.418 \\
12.706 \\
1.611\end{array}$ & $\begin{array}{r}1.855 \\
11 \cdot 622 \\
140 \cdot 265 \\
5 \cdot 151\end{array}$ \\
\hline $\begin{array}{l}\text { SES disadvantaged } \\
\text { K-density } 1500 \mathrm{~m} \text { (mid) } \\
\text { K-density } 1500 \mathrm{~m} \text { (high) } \\
\text { Retail zoning } 1500 \mathrm{~m}\end{array}$ & $\begin{array}{l}1.390 \\
3.329 \\
3.647 \\
1.035\end{array}$ & $\begin{array}{l}0.0147 \\
0.0017 \\
0.0006 \\
0.0474\end{array}$ & $\begin{array}{r}4.016 \\
27 \cdot 896 \\
38 \cdot 339 \\
2 \cdot 814\end{array}$ & $\begin{array}{l}1 \cdot 314 \\
3 \cdot 499 \\
4 \cdot 723 \\
1.012\end{array}$ & $\begin{array}{r}12 \cdot 195 \\
222 \cdot 416 \\
311 \cdot 207 \\
7 \cdot 826\end{array}$ \\
\hline
\end{tabular}

dependent variable was presence/absence of fast food (dichotomous variable) and the independent variables were disadvantaged/advantaged SES, retail kernel density and retail zoning. The disadvantaged group was used as the referent.

There was a statistically significant, inverse relationship between fast-food exposure and the school's SES (disadvantaged: yes/no). More specifically, there was a 1.6 times odds of exposure to fast food within $1000 \mathrm{~m}$ $(\mathrm{OR}=1.634 ; 95 \% \mathrm{CI} 1.017,2.625)$ and a 9.5 times odds of exposure to a fast food within $1500 \mathrm{~m}(\mathrm{OR}=9 \cdot 524 ; 95 \% \mathrm{CI}$ $3.497,25.641)$ around disadvantaged schools compared with schools located in advantaged areas within metropolitan Adelaide. When combining the covariates, the relationship between kernel density of the retail food environment and fast-food exposure adjusted for disadvantage/advantage SES remained positive and statistically significant for both the middle and the upper kernel density tertile groups when compared with the lower tertile. This result suggests a strong positive relationship; that is, as the density of the retail food environment increases, so too does the likelihood of exposure to fast-food outlets within a $1000 \mathrm{~m}$ road network buffer around schools. Similarly, the relationship between disadvantage/advantage SES and fast-food exposure, adjusted for kernel density of the retail food environment and retail zoning, remained negative, still supporting an inverse relationship between disadvantage/ advantage SES and fast-food exposure around schools. However, the association was no longer statistically significant when adjusting for kernel density and retail zoning within a $1000 \mathrm{~m}$ road network buffer around schools. This outcome may result from the strong relationship between kernel density of the retail food environment and fast-food exposure, potentially dominating the model. The same pattern occurred with the $1500 \mathrm{~m}$ buffer around schools within metropolitan Adelaide (Table 4). However, when adjusting for both kernel density and retail zoning, the inverse relationship between SES and fast-food exposure within a $1500 \mathrm{~m}$ buffer around schools remained statistically significant (OR $=4.016$; $95 \%$ CI 1.314, 12.195, $P=0.015)$. As expected, retail zoning was positively associated with the presence of fast food around schools (Table 4).

Table 5 displays results from the zero-inflated Poisson regression model relating the count of fast-food outlets to SES disadvantage/advantage while adjusting for both food retail kernel density and retail zoning within the road network buffers around schools in metropolitan Adelaide. Descriptive statistics (Fig. 2 and Table 3) indicated that schools in disadvantaged areas have on average more fast-food outlets than schools in advantaged areas 
Table 5 Associations between fast food count* and school disadvantaged/advantaged socio-economic status (SES), adjusting for both food retail kernel density (K-density) and retail zoning within the road network buffers around schools, metropolitan Adelaide, South Australia, 2013

\begin{tabular}{|c|c|c|c|c|c|}
\hline \multirow[b]{2}{*}{ Poisson regression } & \multirow[b]{2}{*}{$\beta$ coefficient } & \multirow[b]{2}{*}{$P$ value } & \multirow[b]{2}{*}{$\mathrm{RR} \& \mathrm{OR}=\exp (\beta)$} & \multicolumn{2}{|c|}{$95 \% \mathrm{Cl}$ for $\mathrm{RR}$} \\
\hline & & & & Lower & Upper \\
\hline $\begin{array}{l}\text { SES disadvantaged } 1000 \mathrm{~m} \\
\text { SES disadvantaged } 1500 \mathrm{~m} \\
\text { Logit (fast food }=0 \text { ): }\end{array}$ & $\begin{array}{l}0.403 \\
0.325\end{array}$ & $\begin{array}{l}<0.0001 \\
<0.0001\end{array}$ & $\begin{array}{l}1.495 \\
1.385\end{array}$ & $\begin{array}{l}1.391 \\
1.318\end{array}$ & $\begin{array}{l}1.608 \\
1.456\end{array}$ \\
\hline $\begin{array}{l}\text { Retail zoning } 1000 \mathrm{~m} \\
\text { Logit (fast food }=0 \text { ): }\end{array}$ & -1.578 & $<0.0001$ & 0.206 & 0.125 & 0.340 \\
\hline Retail zoning $1500 \mathrm{~m}$ & $-2 \cdot 770$ & $<0.0001$ & 0.063 & 0.026 & 0.150 \\
\hline $\begin{array}{l}\text { K-density } 1000 \text { m (mid) } \\
\text { K-density } 1000 \text { m (high) } \\
\text { SES disadvantaged }\end{array}$ & $\begin{array}{l}0.961 \\
2.772 \\
0.571\end{array}$ & $\begin{array}{l}<0.0001 \\
<0.0001 \\
<0.0001\end{array}$ & $\begin{array}{r}2.615 \\
15.984 \\
1.770\end{array}$ & $\begin{array}{r}2 \cdot 123 \\
13 \cdot 184 \\
1.645\end{array}$ & $\begin{array}{r}3.214 \\
19.379 \\
1.901\end{array}$ \\
\hline $\begin{array}{l}\text { Logit (fast food }=0): \\
\quad \text { Retail zoning } 1000 \mathrm{~m}\end{array}$ & -1.930 & $<0.0001$ & 0.145 & 0.063 & 0.337 \\
\hline $\begin{array}{l}\text { K-density } 1500 \mathrm{~m} \text { (mid) } \\
\text { K-density } 1500 \mathrm{~m} \text { (high) } \\
\text { SES disadvantaged } \\
\text { Logit (fast food =0): } \\
\text { Retail zoning 1500 m }\end{array}$ & $\begin{array}{l}0.997 \\
2.727 \\
0.439\end{array}$ & $\begin{array}{l}<0.0001 \\
<0.0001 \\
<0.0001\end{array}$ & $\begin{array}{r}2 \cdot 710 \\
15 \cdot 281 \\
1.550\end{array}$ & $\begin{array}{r}2 \cdot 282 \\
12.984 \\
1.475\end{array}$ & $\begin{array}{r}3.217 \\
17.984 \\
1.629\end{array}$ \\
\hline $\begin{array}{l}\text { SES disadvantaged } \\
\text { K-density } 1000 \mathrm{~m} \text { (mid) } \\
\text { K-density } 1000 \mathrm{~m} \text { (high) } \\
\text { Retail zoning } 1000 \mathrm{~m} \\
\text { Logit (fast food }=0 \text { ): }\end{array}$ & $\begin{array}{l}0.564 \\
0.945 \\
2.692 \\
0.707\end{array}$ & $\begin{array}{l}<0.0001 \\
<0.0001 \\
<0.0001 \\
<0.0001\end{array}$ & $\begin{array}{r}1.757 \\
2.573 \\
14.766 \\
2.028\end{array}$ & $\begin{array}{r}1 \cdot 634 \\
2 \cdot 100 \\
12 \cdot 207 \\
1 \cdot 770\end{array}$ & $\begin{array}{r}1 \cdot 890 \\
3 \cdot 153 \\
17 \cdot 861 \\
2 \cdot 323\end{array}$ \\
\hline Retail zoning $1000 \mathrm{~m}$ & -1.039 & 0.0519 & 0.354 & 0.124 & 1.009 \\
\hline $\begin{array}{l}\text { SES disadvantaged } \\
\text { K-density } 1500 \mathrm{~m} \text { (mid) } \\
\text { K-density } 1000 \mathrm{~m} \text { (high) } \\
\text { Retail zoning } 1500 \mathrm{~m} \\
\text { Logit (fast food }=0 \text { ): } \\
\quad \text { Retail zoning } 1500 \mathrm{~m}\end{array}$ & $\begin{array}{l}0.431 \\
0.948 \\
2.657 \\
0.362\end{array}$ & $\begin{array}{l}<0.0001 \\
<0.0001 \\
<0.0001 \\
<0.0001\end{array}$ & $\begin{array}{r}1.538 \\
2.579 \\
14.251 \\
1.436\end{array}$ & $\begin{array}{r}1.464 \\
2 \cdot 173 \\
12 \cdot 099 \\
1.223\end{array}$ & $\begin{array}{r}1.616 \\
3.061 \\
16 \cdot 784 \\
1.686\end{array}$ \\
\hline
\end{tabular}

$\mathrm{RR}$, relative risk.

${ }^{*}$ Poisson regression model for the fast-food count and logit regression model for the absence of fast food (fast food $=0$ ) to predict the membership to the 'certain zero' group; SES disadvantaged=referent; K-density low = referent; retail zoning no=referent; significance was set at 0.05 .

(1.7 times and 1.6 times, respectively, within $1000 \mathrm{~m}$ and $1500 \mathrm{~m}$ buffers around the school). Similar results were observed from the Poisson regression models (Table 5). Indeed, for the $1000 \mathrm{~m}$ buffer, the expected number of fast-food outlets around schools in disadvantaged areas was 1.5 times the expected number of fast-food outlets around schools in advantaged areas ( $\mathrm{RR}=1.495 ; 95 \% \mathrm{CI}$ $1 \cdot 391,1 \cdot 608, P<0 \cdot 0001)$. This relative risk (RR) increased when adjusting for kernel density of the retail food environment $(\mathrm{RR}=1.770$; $95 \%$ CI 1.645, 1.901, $P<0.0001)$. For the $1500 \mathrm{~m}$ buffer, the expected number of fast-food outlets around schools in disadvantaged areas was 1.4 times the expected number of fast-food outlets around schools in advantaged areas ( $\mathrm{RR}=1.385 ; 95 \%$ CI 1.318 , 1.456, $P<0.0001)$. This relative risk increased as well when adjusting for kernel density of the retail food environment $(\mathrm{RR}=1.550 ; 95 \%$ CI 1.475, 1.629, $P<0 \cdot 0001)$. The adjustment for both kernel density and retail zoning did not change the magnitude and the significance of the SES disadvantage/advantage.

As expected, a strong and positive relationship between kernel density of the retail food environment and fast-food outlet count was observed within both the $1000 \mathrm{~m}$ and $1500 \mathrm{~m}$ buffers around schools within metropolitan
Adelaide (Table 5). Similarly, a positive association was observed between retail zoning and fast-food outlets within both the $1000 \mathrm{~m}$ and $1500 \mathrm{~m}$ buffers around schools. Moreover, as fast-food outlets are permitted only within specific zoned areas, 'retail zoning' within $1000 \mathrm{~m}$ and $1500 \mathrm{~m}$ buffers predicted the membership into the 'certain zero' group of schools with no fast food around (inverse relationship), although statistically significant within $1500 \mathrm{~m}$, but borderline within the $1000 \mathrm{~m}$ buffer $(P=0.0519)$. In other words, in areas zoned as retail zones, the observed 'zero counts' of fast food around schools are more likely due to the Poisson counting process, and less likely to be a certain zero. The odds of being a certain zero decreased even when models were adjusted for the kernel density of food retail outlets.

Further models included interaction terms between SES disadvantage/advantage and retail zoning within $1000 \mathrm{~m}$ and $1500 \mathrm{~m}$ buffers (results not shown). Results showed that schools within the $1000 \mathrm{~m}$ buffer retail zoned disadvantaged areas had 1.85 times the expected number of fast-food outlets (RR $=1.850 ; 95 \%$ CI $1.403,2 \cdot 440$, $P<0 \cdot 0001)$ compared with SES advantaged schools. Similarly, schools within the $1500 \mathrm{~m}$ buffer retail zoned disadvantaged areas had 1.16 times the expected number 
of fast-food outlets, compared with SES advantaged schools, but this relative risk was not statistically significant (RR $=1.159 ; 95 \%$ CI $0.847,1.586, P=0.3553)$. For the $1000 \mathrm{~m}$ buffer areas, the effect of SES was almost completely contained in the interaction term (SES $\times$ retail zoning), rendering the adjusted relative risk for SES close to 1 and non-significant. For the $1500 \mathrm{~m}$ buffer areas, the adjusted relative risk of SES was still strong $(\mathrm{RR}=1.906$; 95\% CI $0 \cdot 977,1 \cdot 815, P=0 \cdot 070$ ), although non-significant (borderline of non-significance). In these models (with interaction terms), both kernel density and retail zoning remained strongly and statistically associated with the number of fast-food outlets within both $1000 \mathrm{~m}$ and $1500 \mathrm{~m}$ buffer areas $(P<0 \cdot 0001)$.

\section{Discussion}

The present study investigated fast-food exposure around schools by area SES within metropolitan Adelaide. Results indicated that the odds of exposure to fast food around schools was higher for disadvantaged schools compared with advantaged schools. There was a 9.5 times odds of exposure to fast food within a $1500 \mathrm{~m}$ road network buffer around disadvantaged schools compared with advantaged schools when fast food was measured as the presence/ absence. The inverse, statistically significant relationship was less pronounced but nevertheless still present when investigating exposure to fast food around schools within a $1000 \mathrm{~m}$ buffer, where the odds of exposure was 1.6 times greater in disadvantaged schools. Within the $1000 \mathrm{~m}$ buffer, $82 \%$ (246 out of 300) of disadvantaged schools were exposed to fast food compared with $74 \%$ (106 out of 144) of advantaged schools. This pattern was present even if less pronounced for the $1000 \mathrm{~m}$ buffer, with $79 \%$ of disadvantaged schools in metropolitan Adelaide in proximity to fast-food outlets.

When counting the number of fast-food outlets around schools, there was a 1.6 times greater number of fast-food outlets within a $1500 \mathrm{~m}$ road network buffer around disadvantaged schools than expected, compared with advantaged schools (adjusting for kernel density of food retail). The significant relationship was more pronounced for the count of fast food around schools within a $1000 \mathrm{~m}$ buffer, where the expected number was 1.8 times greater in disadvantaged schools.

The results of the present study support the outcomes from a study in Montreal ${ }^{(25)}$ which investigated the food environment within a $750 \mathrm{~m}$ buffer around schools and concluded that of the $50 \%$ of schools in proximity to fast-food outlets, $81 \%$ were located in the most deprived areas.

Aspects of the built environment such as the growth in exposure to and consumption of fast food are acknowledged as contributing factors to the increasing prevalence of excess body weight in children and adolescents ${ }^{(35)}$.
Energy-dense, nutrient-poor food outlets pose a risk to the health and well-being of children. The proximity of fast food to schools may influence dietary behaviour of students, potentially contributing to energy imbalance and weight gain, particularly among socially underprivileged populations $^{(20)}$.

Higher exposure to fast food for lower-SES schools was supported by several studies with spatial clustering of fastfood outlets highest within $1500 \mathrm{~m}$ of the most socially deprived schools ${ }^{(20-22)}$. The results from the present research indicated that the mean number of fast-food outlets within $1500 \mathrm{~m}$ around schools in metropolitan Adelaide was higher for disadvantaged schools (22.1) compared with advantaged schools (14.2). This was similar to another study where the median number of fastfood outlets increased as the social deprivation of schools increased $^{(19)}$. However, not all studies have reported this association, with one study reporting no association between exposure to fast food and SES, although the authors did report that most schools in their study were exposed to food outlets ${ }^{(24)}$. The difference in findings between some international studies could result from methodological inconsistencies, location-specific discrepancies in the social structure of communities and planning legislation. Nevertheless, the trend of higher exposure to fast food around socially disadvantaged schools was supported ${ }^{(36)}$ and the results of the present research where exposure to fast food proximal to schools was higher in more disadvantaged areas across metropolitan Adelaide aligned with the overall findings of previous studies. A study in Melbourne concluded that lower-SES areas were potentially more obesogenic due to greater exposure to high-energy, nutrient-poor, fast-food outlets ${ }^{(18)}$ and reduced availability of supermarkets compared with high-SES areas ${ }^{(9)}$.

Higher exposure to fast food around schools in low-SES areas within Adelaide may potentially occur in conjunction with decreased accessibility to healthy food options such as the range of produce available in supermarkets. O'Dwyer and Coveney ${ }^{(37)}$ noted a decreased accessibility to supermarkets in Playford, a low-SES local government area in Adelaide, compared with Burnside, a high-SES local government area, and concluded that lower-SES populations have access to fewer resources and are more likely to be more restricted to their immediate food environment ${ }^{(37,38)}$.

As a high number of schools were exposed to retail zoning nearby, a range of mechanisms may be required to limit fast-food accessibility around schools. One option is to use planning policy to list fast-food outlets as 'non-complying' development in proximity to schools, thereby equipping planners with a tool to limit the location of new fast-food outlets around schools to existing uses only and prohibit further proliferation. Despite the potential capability of planning policy and regulation to positively influence the food environment around schools, 
the use of such mechanisms is rare, notwithstanding the mounting evidence highlighting the importance of considering the food environment around schools, particularly accessibility to fast food ${ }^{(25,36,39)}$.

\section{Limitations}

A well-recognised limitation of analyses using geographic information systems-based measures derived from secondary data sources is the possibility for secondary data to misrepresent true food outlet access via including food outlets no longer in operation or failure to account for stores entirely, such as retail food outlets that have recently opened ${ }^{(40)}$. However, previous studies of secondary data sources listing information relevant to food outlets concluded that particular commercial secondary data sources can provide a valid alternative to the costly and time-intensive field observation method ${ }^{(32)}$.

The use of cross-sectional data raises limitations, as does using data sourced over different time periods. Crosssectional data reveal a 'snapshot' in time which may not reflect recent changes to the environment and it was not possible to investigate changes to fast-food exposure around schools of varying SES across different time periods.

The study involved the use of road network buffers, but children may use alternative means of transportation or could potentially follow more flexible routes such as pedestrian and cyclist thoroughfares not included in the road network. Thus, the exposure to fast food of children who walk or cycle to and from school may not follow the road network.

The food environment around schools is just one aspect of food exposure influencing dietary behaviour of schoolaged children. The food environments within schools and within the homes are also likely to contribute to dietary habits and health outcomes of children and adolescents.

\section{Conclusion}

Through the use of geographic information systems and statistical modelling, a number of cross-sectional data sets were analysed to determine the magnitude of fast-food exposure around schools by SES across metropolitan Adelaide. Results indicated that fast-food exposure differed by SES of schools across metropolitan Adelaide. More specifically, there was a 9.5 times greater odds of exposure to fast food within a $1500 \mathrm{~m}$ buffer around schools situated in more disadvantaged areas in Adelaide compared with schools located in advantaged areas.

The higher odds of exposure to fast food near more disadvantaged schools may reflect lower commercial land cost in low-SES areas, potentially creating more financially desirable investments for fast-food developers. Moreover, vulnerable populations within low-SES areas may lack the community knowledge and social capital to protest against the development of unhealthy food retailers or campaign for healthy food retail alternatives, which may require appropriate political support ${ }^{(16)}$.

The food environment may be one factor that contributes to childhood obesity. Australian school-aged children and adolescents from low-SES backgrounds are more likely to be obese compared with students from high-SES backgrounds ${ }^{(13)}$. The food environment around schools has been investigated by some international studies as a potential location for targeted health interventions based on planning policy. The inverse relationship between exposures to fast food near schools and SES is evident across many studies $^{(22,23,25)}$ but not all ${ }^{(24)}$, with calls for such research to be conducted in Australia ${ }^{(36)}$.

The disciplines of health and urban planning are reuniting, reflecting a new range of health concerns and inequalities. The high prevalence of obesity and in particular childhood and adolescent obesity has led to a multi-faced approach to understanding causes of the condition. In particular, the built environment has been assessed as a determinant of health and energy imbalance. The impact of food environments that are less conducive to healthy choices in low-SES areas may be amplified by the fewer resources available to disadvantaged populations to obtain food outside their immediate environment ${ }^{(41)}$.

While students attending schools located in more disadvantaged areas in Adelaide experience greater exposure to fast-food outlets around their school, the potential impact of fast-food exposure on dietary behaviour and BMI of students within metropolitan Adelaide remains unknown. Such information would add to a greater understanding regarding the impact of fast-food exposure on health outcomes.

\section{Acknowledgements}

Financial support: This research received no specific grant from any funding agency in the public, commercial or not-for-profit sectors. Conflict of interest: None. Authorship: N.T.C. conceived the research; H.P.K. and N.T.C. created and ran all the spatial data and analyses; H.P.K., T.N. and N.T.C. analysed the data. All authors were involved writing the paper and all authors have approved the final manuscript. Ethics of buman subject participation: Not applicable.

\section{Supplementary material}

To view supplementary material for this article, please visit http://dx.doi.org/10.1017/\$1368980016001385

\section{References}

1. World Health Organization (2000) Obesity: Prevention and Managing the Global Epidemic. Report of a WHO Consultation. WHO Technical Report Series no. 894. Geneva: WHO 
2. Prentice AM (2006) The emerging epidemic of obesity in developing countries. Int J Epidemiol 35, 93-99.

3. Roth J, Qiang X, Marbán SL et al. (2004) Obesity pandemic: where have we been and where are we going? Obes Res $\mathbf{1 2}$, Suppl. 2, 88S-101S.

4. Ng M, Fleming T, Robinson M et al. (2014) Global, regional, and national prevalence of overweight and obesity in children and adults during 1980-2013: a systematic analysis for the Global Burden of Disease Study 2013. Lancet 384, 766-781.

5. Australian Bureau of Statistics (2013) Australian Health Survey: Updated Results, 2011-2012. Canberra: ABS.

6. World Health Organization (2003) Diet, Nutrition and the Prevention of Chronic Diseases. Joint WHO/FAO Expert Consultation. WHO Technical Report Series no. 916. Geneva: WHO.

7. Inagami S, Cohen D, Brown A et al. (2009) Body mass index, neighbourhood fast food and restaurant concentration, and car ownership. J Urban Health 86, 683-695.

8. Thompson O, Ballew C, Resnicow K et al. (2003) Food purchased away from home as a predictor of change in BMI z-score among girls. Int J Obes Relat Metab Disord 28, 282-289.

9. Burns C \& Inglis A (2007) Measuring food access in Melbourne: access to healthy and fast foods by car, bus and foot in an urban municipality in Melbourne. Health Place 13, 877-885.

10. James P, Troped PJ \& Laden F (2013) The impact of the built environment on health. In Women and Health, 2nd ed., pp. 753-763 [MB Goldman, R Troisi and KM Rexrode, editors]. London: Academic Press.

11. Williams J, Scarborough P, Matthews A et al. (2014) A systematic review of the influence of the retail food environment around schools on obesity-related outcomes. Obes Rev 15, 359-374.

12. Black C, Moon G \& Baird J (2014) Dietary inequalities: what is the evidence for the effect of the neighbourhood food environment? Health Place 27, 229-242.

13. O'Dea JA (2008) Gender, ethnicity, culture and social class influences on childhood obesity among Australian schoolchildren: implications for treatment, prevention and community education. Health Soc Care Community 16, 282-290.

14. Lewis LB, Sloane DC, Nascimento LM et al. (2005) African Americans' access to healthy food options in South Los Angeles restaurants. Am J Public Health 95, 668-673.

15. Block J, Scribner R \& De Salvo K (2004) Fast food, race/ ethnicity, and income: a geographic analysis. Am J Prev Med 27, 211-217.

16. Smoyer-Tomic K, Spence J, Raine K et al. (2008) The association between neighborhood socioeconomic status and exposure to supermarkets and fast food outlets. Health Place 14, 740-754.

17. Macintyre S, McKay L, Cummins S et al. (2005) Out-of-home food outlets and area deprivation: case study in Glasgow, UK. Int J Behav Nutr Phys Act 2, 16.

18. Reidpath D, Burns C, Garrard J et al. (2002) An ecological study of the relationship between social and environmental determinants of obesity. Health Place 8, 141-145.

19. Rosenshein L \& Waters L (2009) The effect of healthy food accessibility on childhood obesity. In Proceedings of the 17 th International Conference on Geoinformatics, George Mason University, Fairfax, Virginia, USA, 12-14 August 2009. http://ieeexplore.ieee.org/xpls/abs_all.jsp?arnumber= 5293562 (accessed June 2016).

20. Day P \& Pearce J (2010) Obesity-promoting food environments and the spatial clustering of food outlets around schools. Am J Prev Med 40, 113-121.
21. Simon A, Kwan D, Angelescu A et al. (2008) Proximity of fast food restaurants to schools: do neighborhood income and type of school matter? Prev Med 47, 284-288.

22. Zenk S \& Powell L (2008) US secondary schools and food outlets. Health Place 14, 336-346.

23. Pearce J, Blakely T, Witten K et al. (2007) Neighborhood deprivation and access to fast-food retailing: a national study. Am J Prev Med 32, 375-382.

24. Ellaway A, Macdonald L, Lamb K et al. (2012) Do obesitypromoting food environments cluster around socially disadvantaged schools in Glasgow, Scotland? Health Place 18, $1335-1340$.

25. Kestens Y \& Daniel M (2010) Social inequalities in food exposure around schools in an urban area. Am J Prev Med 39, 33-40.

26. Australian Bureau of Statistics (2013) Census of Population and Housing: Basic Community Profile DataPack, 2011 Third Release. Canberra: ABS.

27. Australian Bureau of Statistics (2013) Technical Paper: Socio-Economic Indexes for Areas (SEIFA) 2011. Canberra: ABS.

28. Australian Bureau of Statistics (2010) Australian Statistical Geography Standard (ASGS): Volume 1 - Main Structure and Greater Capital City Statistical Areas. Canberra: ABS.

29. Niyonsenga T, Courteau J, Dean C et al. (2009) Geomatics, epidemiology and bioStatistics: an application to acute coronary syndrome. In Interfacing Geostatistics and GIS, pp. 249-260 [J Pilz, editor]. Berlin/Heidelberg: SpringerVerlag.

30. Pampalon R, Hamel D, Gamache P et al. (2009) A deprivation index for health planning in Canada. Chronic Dis Can 29, 178-191.

31. Taylor BT, Fernando P, Bauman AE et al. (2011) Measuring the quality of public open space using Google Earth. Am J Prev Med 40, 105-112.

32. Paquet C, Daniel M, Kestens Y et al. (2008) Field validation of listings of food stores and commercial physical activity establishments from secondary data. Int J Behav Nutr Phys Act 5, 58.

33. Morris J \& Hardman A (1997) Walking to health. Sports Med 23, 306-332.

34. Kloog I, Haim A \& Portnov BA (2009) Using kernel density function as an urban analysis tool: investigating the association between nightlight exposure and the incidence of breast cancer in Haifa, Israel. Comput Environ Urban Syst 33, 55-63.

35. Anderson P \& Butcher K (2006) Childhood obesity: trends and potential cause. Future Child 16, 19-45.

36. Kent J, Thompson S \& Jalaludin B (2011) Healthy Built Environments: A Review of the Literature. Sydney: University of New South Wales, Program HBE.

37. O'Dwyer LA \& Coveney J (2006) Scoping supermarket availability and accessibility by socio-economic status in Adelaide. Health Promot J Aust 17, 240-246.

38. Coveney J \& O'Dwyer LA (2009) Effects of mobility and location on food access. Health Place 15, 45-55.

39. Davis B \& Carpenter C (2009) Proximity of fast-food restaurants to schools and adolescent obesity. Am J Public Health 99, 505-510.

40. Liese A, Colabianshi N, Lamichhane A et al. (2010) Validation of 3 food outlet databases: completeness and geospatial accuracy in rural and urban food environments. Am J Epidemiol 172, 1324-1333.

41. White M (2007) Food access and obesity. Obes Rev 8, 99-107. 